\title{
Analysis of the vascular responses in a murine model of polycystic ovary syndrome
}

\author{
Sieneke Labruijere ${ }^{1}$, E Leonie A F van Houten ${ }^{2}$, René de Vries ${ }^{1}$, \\ Usha M Musterd-Bagghoe', Ingrid M Garrelds' ${ }^{1}$, Piet Kramer ${ }^{2}$, A H Jan Danser', \\ Carlos M Villalón ${ }^{3}$, Jenny A Visser ${ }^{2}$ and Antoinette MaassenVanDenBrink ${ }^{1}$ \\ ${ }^{1}$ Division of Vascular Medicine and Pharmacology and ${ }^{2}$ Division of Endocrinology, Department of Internal Medicine, \\ Erasmus MC, PO Box 2040, 3000 CA Rotterdam, The Netherlands \\ ${ }^{3}$ Departamento de Farmacobiología, Cinvestav-Coapa, Calzada de los Tenorios 235, Col. Granjas-Coapa, Delegación \\ Tlalpan, CP 14330 México D.F., Mexico
}

\begin{abstract}
Polycystic ovary syndrome (PCOS) is the most common endocrine disorder in women of the reproductive age, but the exact pathophysiological mechanisms involved remain unclear. Cardiovascular disease risk is increased in PCOS patients and endothelial damage has been observed. We recently developed a mouse model of PCOS with reproductive and metabolic characteristics resembling those observed in women with PCOS. In this model we studied vascular function with particular emphasis on markers of vascular endothelial function. Animals were treated for 90 days with dihydrotestosterone (DHT; $27.5 \mu \mathrm{g} /$ day) or placebo using subcutaneous continuous-release pellets. Aortas were isolated for isometric force recordings in organ baths to investigate endothelial and vascular smooth muscle characteristics. Lungs were used to analyze endothelial nitric oxide synthase (eNOS) expression and phosphorylation. Asymmetric dimethylarginine (ADMA) levels were investigated in serum to assess endothelial damage. Expression of androgen receptor ( $A r)$ mRNA was studied in aortas. DHT treatment (compared with placebo) induced i) a significant decrease in acetylcholine-induced aortic relaxations, with no change in calcitonin generelated peptide- or sodium nitroprusside-induced relaxations, as well as 5-hydroxytryptamine-induced contractions; ii) no change in eNOS expression/phosphorylation in lungs or in plasma ADMA levels; and iii) a twofold increase in aortic AR expression. Our results suggest that, in DHT-exposed mice, hyperandrogenemia specifically decreases endotheliumdependent vasorelaxation without deterioration of smooth muscle function. This study may initiate further investigations to elucidate underlying mechanism for the phenotype that is present in these animals, as well as in PCOS patients.
\end{abstract}

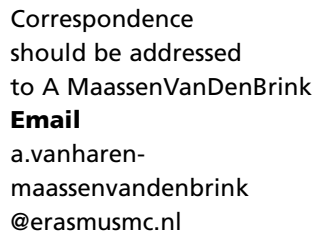


subpopulations (Rodin et al. 1998, Davis et al. 2002, Goodarzi et al. 2005). The exact mechanisms involved in the pathophysiology of PCOS are still unclear, but high levels of androgens are considered to play a crucial role in the etiology. PCOS patients suffer from dyslipidemia, obesity and metabolic syndrome (Wild 2002, Glueck et al. 2009), resulting in an increased risk for type 2 diabetes mellitus and cardiovascular diseases including hypertension and atherosclerosis (Charitidou et al. 2008, Wild et al. 2010, Goodarzi et al. 2011, de Groot et al. 2011). This predisposition is further aggravated by the associated endothelial dysfunction (Lakhani et al. 2005, Hudecova et al. 2010). Studies in PCOS women showed increased circulating levels of asymmetric dimethylarginine (ADMA), a marker of endothelial dysfunction. ADMA is a competitive inhibitor of nitric oxide synthase (NOS), thus increased ADMA levels can lead to decreased vascular relaxation. ADMA levels are often increased in cardiovascular diseases (Charitidou et al. 2008, Bayrak et al. 2012). Endothelial dysfunction in women with PCOS is often assessed by measuring flow-mediated dilation (FMD) of the brachial artery and intima media thickness of the carotid artery (CIMT). A decreased FMD and an increased CIMT have been observed in women with PCOS compared with normo-ovulatory woman (Kravariti et al. 2005, Meyer et al. 2009). Also women with PCOS often display increased insulin resistance. Insulin resistance is thought to be correlated with endothelial dysfunction and thus might play an important role in the development of endothelial dysfunction (Suzuki et al. 2007, Stepto et al. 2013). In addition, serum paraoxonase 1 (PON1) activity is decreased in women with PCOS (Soyman et al. 2011, Bayrak et al. 2012). PON1 is a HDL-associated enzyme that prevents LDL oxidation and thereby prevents the negative effects of LDL. Furthermore, hypertensive, but not normotensive, PCOS women displayed increased arterial stiffness (Sasaki et al. 2011). Taken together, these studies suggest that women with PCOS have impaired vascular function, which may be assigned at least partly to impaired endothelial function. However, the relationship between hyperandrogenemia and endothelial dysfunction remains unclear. The results of studies on the effects of androgens on vascular reactivity in women are controversial and probably depend on the exposure period and endogenous estradiol levels in women (Vitale et al. 2010). In females taking high doses of androgens decreased vascular function was found, which was assigned to a negative effect of testosterone on endothelial NOS (eNOS)-mediated responses (McCredie et al. 1998). It is unknown whether the effects of testosterone on endothelial function are direct effects mediated through the androgen receptor (AR) or indirect effects mediated via the conversion of testosterone into estrogens. The direct effect of androgens can be experimentally investigated by studying the effects of the nonaromatizable androgen dihydrotestosterone (DHT) on endothelial function.

Several experimental animal models for PCOS have been developed through prenatal or postnatal exposure to androgens, but these animal models were mainly used to investigate ovarian and metabolic function and the vascular phenotype was not studied (Manneras et al. 2007, Roland et al. 2010). In pregnant rats treated with testosterone, increased blood pressure and decreased endothelial function were observed (Chinnathambi et al. 2013). Recently, we have developed a mouse model of PCOS, facilitating future use of transgenic animals, in which prepubertal female mice were exposed to DHT for 90 days. These DHT-exposed mice display both reproductive and metabolic characteristics resembling those observed in women with PCOS, such as acyclicity, cyst-like follicles, increased adiposity, increased leptin and decreased adiponectin levels, and impaired glucose tolerance (van Houten et al. 2012). We used this mouse PCOS model to study the effect of hyperandrogenemia on vascular function. The effect of DHT on in vitro vascular responses to several vasoactive agents was analyzed, with particular emphasis on markers of vascular endothelial function (i.e. lung expression/phosphorylation of eNOS and serum levels of ADMA).

\section{Materials and methods}

\section{Animals}

C57BL/6J mice at postnatal day 19 were s.c. implanted with a 90-day continuous-release pellet containing either DHT $(2.5 \mathrm{mg}, 27.5 \mu \mathrm{g} /$ day; $n=14)$ or placebo $(n=16$; Innovative Research of America, Sarasota, FL, USA) as described previously (van Houten et al. 2012). A separate group of mice was implanted with a 60-day release DHT pellet ( $1.5 \mathrm{mg}, 25 \mu \mathrm{g} /$ day; $n=9)$ or placebo $(n=9$; Innovative Research of America). Mice were killed at the end of the treatment period (60 or 90 days). Blood samples were collected by orbital puncture after the mice were anesthetized with isoflurane. Mice were killed by decapitation and tissues were isolated. The same animals as reported in the study by van Houten et al. (2012) were used in this study.

Mice were kept under standard animal housing conditions in accordance with the National Institutes of

Published by Bioscientifica Ltd. 
Health Guidelines for the Care and Use of Experimental Animals. The experiments were performed with permission of the Local Ethics Committee.

\section{Tissues}

Thoracic aortas from the 60- $(n=18)$ and 90-day-treated animals $(n=18)$ were placed in cold Krebs buffer $\left(4^{\circ} \mathrm{C}\right)$, aerated with $5 \% \mathrm{CO}_{2}$ and $95 \% \mathrm{O}_{2}$ and stored overnight for organ bath experiments (composition of Krebs buffer in $\mathrm{mmol} / \mathrm{l}: \mathrm{NaCl} 118, \mathrm{KCl}$ 4.7, $\mathrm{CaCl}_{2} 2.5, \mathrm{MgSO}_{4} 1.2, \mathrm{KH}_{2} \mathrm{PO}_{4}$ 1.2, $\mathrm{NaHCO}_{3} 25$ and glucose 8.3; pH 7.4). In addition, aorta segments of the 90-day-treated mice $(n=12)$ were directly snap frozen in liquid nitrogen and stored at $-80^{\circ} \mathrm{C}$ until RNA isolation. Furthermore, from the 90-day-treated animals, the lungs were collected $(n=6$ for both DHT- and placebo-treated animals) and cut into pieces. Pieces were divided into two groups and incubated for $1 \mathrm{~min}$ with either vehicle or $100 \mu \mathrm{mol} / \mathrm{l}$ acetylcholine in Krebs buffer. Samples were snap frozen in liquid nitrogen and stored at $-80^{\circ} \mathrm{C}$ for protein isolation. Lungs were used for this experiment, because lungs are very densely vascularized with small resistance vessels. A small amount of blood serum was available from all the treatment groups and was used for the measurement of ADMA as a measure of endothelial damage.

\section{Functional experiments}

Two-millimeter aortic rings (inner diameter 1-2 mm) were mounted in organ baths (Danish Myo Technology, Aarhus, Denmark) between two aluminum wires (wire diameter $40 \mu \mathrm{m}$ ), which were attached to a force displacement transducer and a computer on one side and a displacement device on the other side. The temperaturecontrolled organ baths $\left(37^{\circ} \mathrm{C}\right)$ were filled with Krebs buffer and aerated with $5 \% \mathrm{CO}_{2}$ and $95 \% \mathrm{O}_{2}$. The tension of the aortic rings was normalized to $90 \%$ of the estimated diameter at $100 \mathrm{mmHg}$ pressure and stabilized for $30 \mathrm{~min}$ (Mulvany \& Halpern 1977).

The rings were exposed to $30 \mathrm{mmol} / 1 \mathrm{KCl}$ and after washout to $100 \mathrm{mmol} / \mathrm{K} \mathrm{KCl}$ to compare reactivity and maximal contractile response of the different rings. For vasodilator studies, rings were precontracted with 10-100 nmol/1 U46619, a thromboxane $\mathrm{A}_{2}$ analog, until a contraction of $50 \%$ of the contraction induced by $100 \mathrm{mmol} / \mathrm{l} \mathrm{KCl}$ was reached. Smooth muscle cell-dependent vasorelaxation was determined in response to increasing concentrations of the vasodilating compounds calcitonin gene-related peptide (CGRP; rat $\alpha$-CGRP,
NeoMPS, Polypeptide Group; Strasbourg, France) and sodium nitroprusside (SNP; Sigma Chemical Co.). CGRP activates the CGRP receptor present in smooth muscle cells (Eftekhari \& Edvinsson 2010). SNP stimulates the direct release of NO, which can enter the smooth muscle cells (Friederich \& Butterworth 1995). Endothelium-dependent responses were examined using acetylcholine (Sigma Chemical Co.). To measure the maximal relaxation, $100 \mu \mathrm{mol} / 1 \mathrm{SNP}$ were added following the relaxation experiments to CGRP and acetylcholine. Contractile responses were investigated with increasing concentrations of the vasoconstrictor 5-hydroxtryptamine (5-HT; Sigma Chemical Co.). Half of the rings of the 90-day DHTtreatment group were first incubated for $30 \mathrm{~min}$ with $100 \mu \mathrm{mol} / \mathrm{l}(6 \mathrm{R})-5,6,7,8$-tetrahydro-L-biopterin·2HCl (BH4) (Calbiochem, Merck KGaA, Darmstadt, Germany) (an inhibitor of both reactive oxygen species (ROS) and eNOS uncoupling), $30 \mu \mathrm{mol} / \mathrm{l} \mathrm{N}$-acetyl-cysteine (NAC; Sigma Chemical Co.) or $100 \mu \mathrm{mol} / 1$ tempol (Sigma Chemical Co.; both ROS inhibitors) prior to precontraction with U46619. These concentrations have been determined previously (Durik et al. 2012). SNP, acetylcholine and 5-HT were dissolved in bidistilled water; NAC and tempol were both dissolved in DMSO.

\section{Quantitative real-time RT-PCR}

RNA of thoracic aortas was isolated using an RNA isolation kit for fibrous tissue (RNEasy fibrous tissue; Qiagen). RNA was reverse transcribed using the QuantiTect RT kit. A quantitative real-time RT-PCR was performed using TaqMan probes for the AR and $\beta$-actin as a housekeeping gene (Applied Biosystems). The expression of the target gene was normalized to the expression levels of $\beta$-actin using the $2^{-\Delta \Delta C t}$ method.

\section{Quantification of eNOS phosphorylation using western blotting}

Lung tissue was isolated, cut into small pieces and incubated with acetylcholine $(100 \mu \mathrm{mol} / \mathrm{l})$ or vehicle (Krebs buffer) for $1 \mathrm{~min}$. Western blotting was performed with $15 \mu \mathrm{g}$ of protein using total eNOS antibody (diluted 1:1000) or phosphorylated eNOS (Ser1177) antibody (diluted 1:1000). For visualization, a peroxidase-conjugated goat anti-rabbit antibody was used (all antibodies were obtained from Santa Cruz Biotechnology). The blot was scanned and analyzed with the use of ImageJ Software (NIH, Bethesda, MD, USA).

Published by Bioscientifica Ltd. 


\section{ADMA levels}

Blood serum was collected from all treatment groups and serum levels of ADMA were measured using the ADMA ELISA kit (DLD Diagnostika GmbH, Hamburg, Germany).

\section{Statistical analysis}

The relaxant responses elicited by the vasorelaxant compounds were expressed as percentage of the maximum contraction induced by U46619 (10-100 nmol/1, 100\%). The contractile responses to 5 -HT were expressed as percentage of the previous response to $100 \mathrm{mmol} / \mathrm{l} \mathrm{KCl}$. All data are presented as mean \pm s.E.M. Statistical analysis of the concentration response curves was accomplished with GraphPad Prism 5 Software (La Jolla, CA, USA), using unpaired $t$-tests and ANOVA. Moreover, differences in $\% A R$ expression (compared with the household gene $\beta$-actin using the $2^{-\Delta \Delta C t}$ method) and the differences in eNOS expression and phosphorylation between the treatment groups were assessed using an unpaired $t$-test. Statistical significance was accepted at $P<0.05$ in all cases.

\section{Results}

\section{Effect of 90 days DHT exposure on acetylcholine-induced relaxation in thoracic aortas}

Acetylcholine-induced maximal relaxations were significantly smaller in aortas from 90-day DHT-treated mice than in those from placebo-treated mice ( $P=0.04$; Fig. $1 \mathrm{~A})$. The $\mathrm{pEC}_{50}$ values did not differ between DHT- and placebo-treated animals (Table 1). Furthermore, no difference was observed in response to $100 \mu \mathrm{mol} / \mathrm{l} \mathrm{SNP}$,

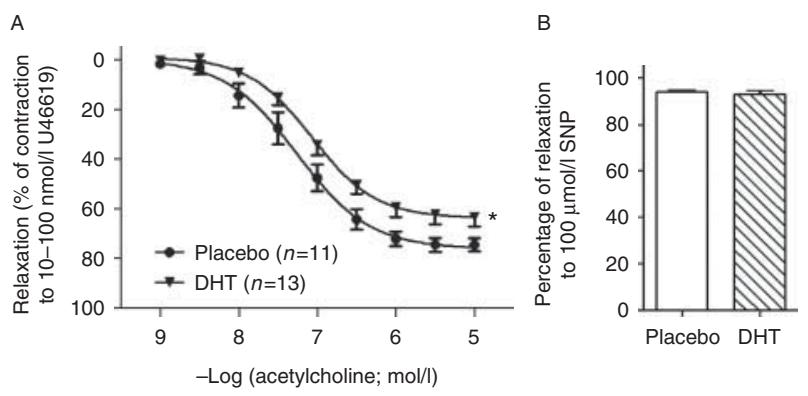

\section{Figure 1}

(A) Relaxations to acetylcholine in mice thoracic aortas after chronic treatment with DHT during 90 days. (B) Subsequently, the vasorelaxation to $100 \mu \mathrm{mol} / \mathrm{l}$ SNP was measured. All values are relative to precontraction with $10-100 \mathrm{nmol} / \mathrm{l}$ U46619. *Significantly different from placebo, $P<0.05$.
Table $1 E_{\max }$ and $p E C_{50}$ values for acetylcholine, CGRP, SNP and 5 -HT in aortas of mice treated for 90 days with DHT or placebo

\begin{tabular}{|c|c|c|c|c|}
\hline & \multicolumn{2}{|c|}{ Placebo 90 days } & \multicolumn{2}{|c|}{ DHT 90 days } \\
\hline & $E_{\max }(\%)$ & $\mathrm{pEC}_{50}$ & $E_{\max }(\%)$ & $\mathrm{pEC}_{50}$ \\
\hline Acetylcholine & $75 \pm 3$ & $7.2 \pm 0.1$ & $64 \pm 4^{*}$ & $7.1 \pm 0.1$ \\
\hline CGRP & $89 \pm 13$ & $8.3 \pm 0.1$ & $99 \pm 3$ & $8.3 \pm 0.1$ \\
\hline SNP & $96 \pm 7$ & $7.5 \pm 0.1$ & $91 \pm 8$ & $7.4 \pm 0.1$ \\
\hline $5-\mathrm{HT}$ & $96 \pm 7$ & $6.9 \pm 0.1$ & $91 \pm 8$ & $6.8 \pm 0.1$ \\
\hline
\end{tabular}

*Significantly different from placebo, $P<0.05$.

which was added after the concentration response curve to acetylcholine was finished (Fig. 1B).

\section{Effect of 90 days DHT exposure on SNP- and CGRP-induced relaxations and 5 -HT-induced contractions}

In contrast to the relaxation response to acetylcholine described above, the maximal relaxations and $\mathrm{pEC}_{50}$ values to CGRP (Fig. 2A) and SNP (Fig. 2C) were not different between the 90-day DHT- and placebo-treated groups. Furthermore, no difference was observed in the subsequent response induced by $100 \mu \mathrm{mol} / \mathrm{l}$ SNP after the CGRP curve (Fig. 2B). Likewise, no differences were observed in the concentration response curves to 5-HT (Fig. 2D), $E_{\max }$ and $\mathrm{pEC}_{50}$ values are shown in Table 1.

\section{Effect of BH4, NAC or tempol on the relaxations to acetylcholine in $\mathbf{9 0}$ days DHT-exposed vessels}

Since impaired endothelial function might be caused by a decreased NO bioavailability or decreased NO production by eNOS, the relaxations to acetylcholine were also measured in the presence of $100 \mu \mathrm{mol} / 1 \mathrm{BH} 4,30 \mu \mathrm{mol} / 1 \mathrm{NAC}$ or $100 \mu \mathrm{mol} / 1$ tempol in thoracic aortas of mice treated for 90 days with placebo and DHT to investigate the role of ROS and eNOS uncoupling in the acetylcholine response. Both NAC and tempol are ROS inhibitors and BH4 is needed for eNOS functioning. Thirty minutes of incubation with NAC or tempol did not cause any difference in acetylcholineinduced relaxation in DHT- or placebo-treated mice (Fig. 3A and $\mathrm{B})$. Interestingly, whereas incubation with $\mathrm{BH} 4$ had no effect on the acetylcholine-induced maximal vasorelaxation in placebo-treated mice, it induced a significant increase in vasorelaxation in DHT-treated animals ( $E_{\max \text { DHT }} 64 \pm 4 \% \mathrm{vs}$ $\left.E_{\text {max } \mathrm{DHT}+\mathrm{BH} 4}: 81 \pm 3 \%, P=0.02\right)$. The $\mathrm{pEC}_{50}$ values did not differ $\left(\mathrm{pEC}_{50}\right.$ DHT: $7.1 \pm 0.1$ vs $\mathrm{pEC}_{50}$ DHT $+\mathrm{BH} 4: 6.8 \pm 0.1$, $P=0.4$; Fig. 3B).

Published by Bioscientifica Ltd. 
A

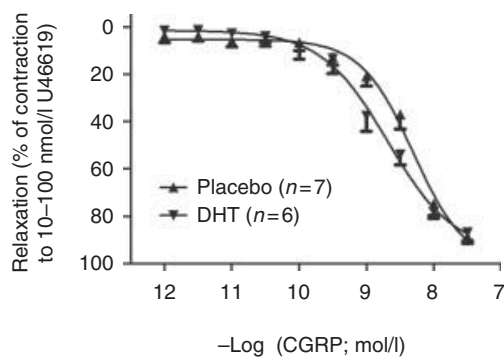

B
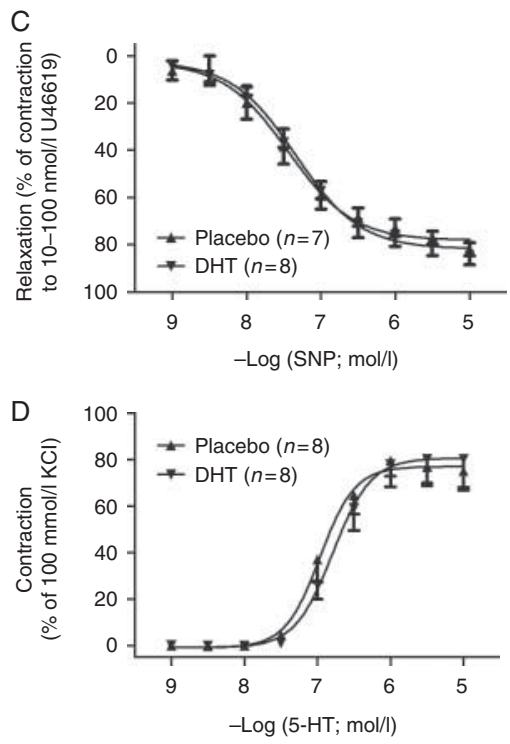

Figure 2

Relaxations to CGRP and relaxations to $100 \mu \mathrm{mol} / \mathrm{l}$ SNP after relaxations to (A) CGRP, as well as relaxations to (B and C) SNP and contractions to (D) 5-HT after 90 days of treatment with DHT or placebo.

\section{Endothelial damage as a primary or secondary phenomenon}

To investigate whether the endothelial damage that we observed was a consequence of the metabolic changes in the DHT-treated mice, we studied relaxations to acetylcholine and SNP in mice that were treated with DHT for 60 days. DHT treatment for 60 days induced neither a reproductive nor a metabolic phenotype (results not shown), but also resulted in significantly lower plasma DHT levels at the end of the treatment period compared with the animals that were treated with the 90-day release pellet $(0.8 \pm 0.1$ vs $2.81 \pm 0.3 \mathrm{nmol} / 1, P<0.05)$. Comparable with the 90-day treatment group, acetylcholineinduced maximal relaxations were significantly smaller in aortas from 60-day DHT-treated mice than in those from placebo-treated mice $(P=0.04$; Fig. $4 \mathrm{~A})$. The $\mathrm{pEC}_{50}$ values did not differ between DHT- and placebo-treated animals (Table 2). Furthermore, no difference was observed in response to $100 \mu \mathrm{mol} / \mathrm{l} \mathrm{SNP}$, which was added after the concentration response curve to acetylcholine had been finished (Fig. 4B).

\section{Expression and phosphorylation of eNOS as well as serum levels of ADMA}

To investigate whether there were differences in eNOS availability and functioning between the treatment groups, total eNOS and eNOS activation through Ser1177 phosphorylation were analyzed in lungs of 90-day placebo- and DHT-treated animals after 1 min incubation with acetylcholine or vehicle. Values were corrected for $\beta$-actin expression. No differences were seen in the total expression level of eNOS (Fig. 5A). Also DHT treatment had no effect on the eNOS Ser1177 phosphorylation level (Fig. 5B). Likewise, serum levels of ADMA, a competitive inhibitor of eNOS, did not significantly differ between 90-day DHT- and placebo-treated animals (Fig. 6).
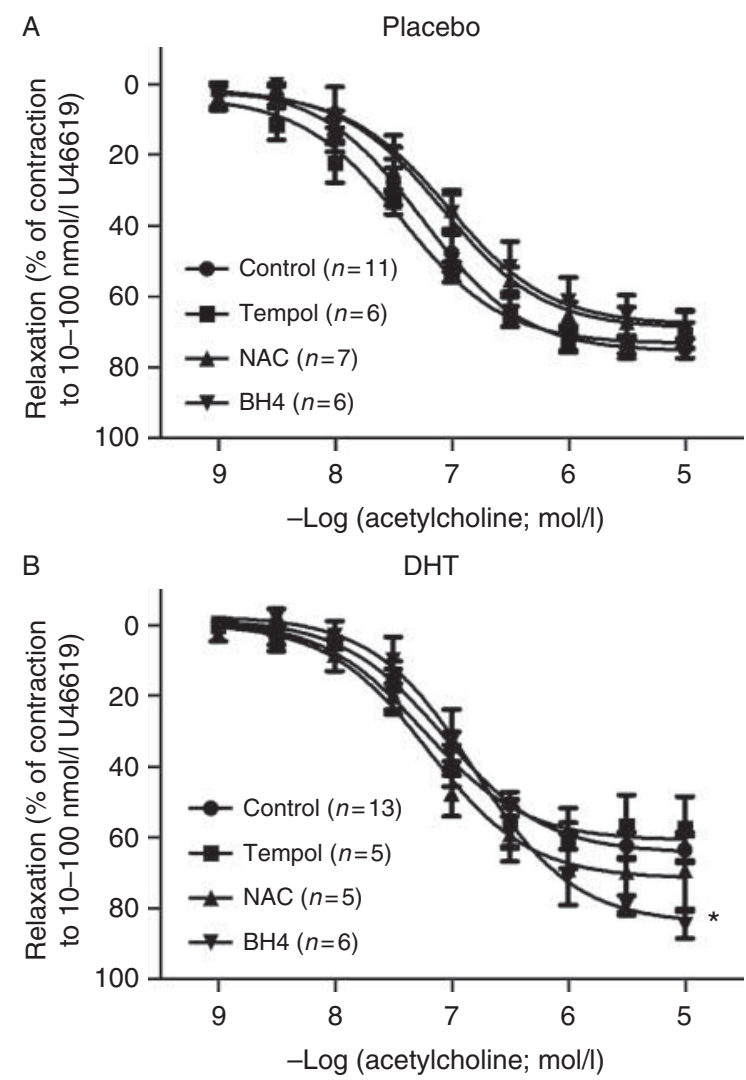

Figure 3

Acetylcholine-induced relaxations after 30-min incubation with $\mathrm{BH} 4$, NAC or tempol in (A) placebo- and (B) DHT-treated animals. *Significantly different from placebo, $P<0.05$. 
A

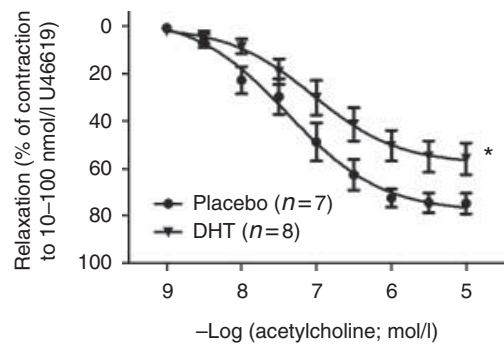

B

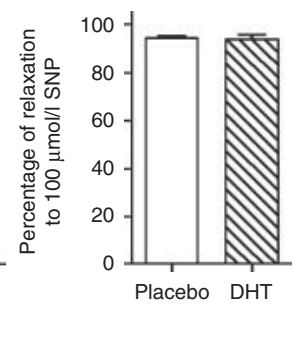

Figure 4

(A) Relaxations to acetylcholine in mice thoracic aortas after chronic treatment with DHT during 60 days. (B) Subsequently, the vasorelaxation to $100 \mu \mathrm{mol} / \mathrm{l}$ SNP was measured. All values are relative to precontraction with $10-100 \mathrm{nmol} / \mathrm{l}$ U46619. *Significantly different from placebo, $P<0.05$.

\section{Effect of DHT exposure on Ar mRNA expression in thoracic aortas}

To investigate if AR signaling might be involved in the difference in endothelial functioning between the DHT- and placebo-treated animals, $A r$ expression was examined. A 2.2-fold increase in $A r$ mRNA expression was observed in thoracic aortas of mice treated for 90 days with DHT when corrected for $\beta$-actin expression $(P=0.02$; Fig. 7$)$.

\section{Discussion}

\section{General}

Our results show that in aortic vessels chronic DHT exposure i) specifically decreased the vasodilatation to acetylcholine but not that to vasodilators directly acting at the smooth muscle layer, such as SNP and ii) increased Ar mRNA expression. This implies a decreased endothelial function, unrelated to a deterioration of vascular smooth muscle function and/or an eNOS decreased expression/ phosphorylation. These results suggest that this DHTinduced mouse model, besides having a PCOS-resembling metabolic and reproductive phenotype, also has a vascular phenotype. This mouse model for PCOS therefore may be an interesting model to investigate the cardiovascular alterations observed in PCOS patients.

\section{Specific decrease in aortic endothelial function after DHT treatment in mice: resemblance with other PCOS experimental models}

Our data show that the aortic vasodilatation to acetylcholine, which acts on the vascular endothelium to induce vascular smooth muscle relaxation (Furchgott \& Zawadzki 1980), was significantly decreased after chronic treatment with DHT. In contrast, the vasodilatation to SNP, an NO donor acting directly on vascular smooth muscle, remained unaffected. These findings suggest that chronic DHT treatment results in a decreased aortic endothelial function. Consistent with this conclusion, the concentration response curves to the direct vasodilator CGRP and to the vasoconstrictor 5-HT remained unaffected upon chronic DHT exposure. Because CGRP and 5-HT receptors have been shown to be present on the membrane of vascular smooth muscle cells and, therefore, can produce direct vascular effects (Furchgott \& Zawadzki 1980, Villalon \& Centurion 2007, Villalon \& Olesen 2009), our findings suggest that chronic DHT treatment does not cause deterioration of vascular smooth muscle function. In contrast, in a rat model of PCOS, contractions to noradrenaline, mediated via the PLC signaling pathway similarly as contractions to 5-HT in our model, were decreased (Sara et al. 2012). Thus, although contractions to 5-HT remained unaffected after chronic DHT treatment, we cannot exclude that the effect of other constrictors might be affected in our model. On the other hand, our results are in agreement with a recent study in a DHT-induced rat PCOS model, using a comparable DHT treatment schedule as in our mouse study, where DHT treatment resulted in specific decrease in acetylcholine-induced vasodilator responses (Keller et al. 2011). Endothelial dysfunction was also observed in a rat PCOS model developed by daily injections of the antiprogestin mifepristone (Lakhani et al. 2006). Clearly, endothelial dysfunction can be a predictor of cardiovascular disease or hypertension. This is also seen in women with PCOS (Wild et al. 2010, Goodarzi et al. 2011, de Groot et al. 2011); therefore it is important to elucidate the underlying mechanisms for the development of better treatment options.

Table $2 E_{\max }$ and $\mathrm{pEC}_{50}$ values for acetylcholinein aortas of mice treated for 60 days with DHT or placebo

\begin{tabular}{|c|c|c|c|c|}
\hline & \multicolumn{2}{|c|}{ Placebo 60 days } & \multicolumn{2}{|c|}{ DHT 60 days } \\
\hline & $\mathrm{E}_{\max }(\%)$ & $\mathrm{pEC}_{50}$ & $\mathrm{E}_{\max }(\%)$ & $\mathrm{pEC}_{50}$ \\
\hline Acetylcholine & $75 \pm 4$ & $7.3 \pm 0.2$ & $56 \pm 4^{*}$ & $7.2 \pm 0.3$ \\
\hline
\end{tabular}

*Significantly different from placebo, $P<0.05$.

Published by Bioscientifica Ltd. 

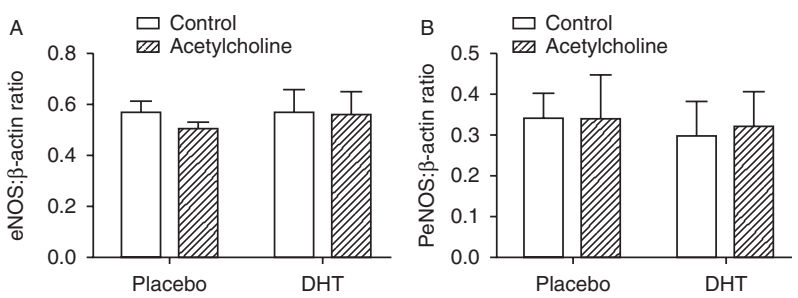

Figure 5

(A) eNOS and (B) Ser1177 phosphorylated eNOS expression in the lungs of mice treated for $1 \mathrm{~min}$ with acetylcholine $(100 \mu \mathrm{mol} / /$; placebo $n=7$, DHT $n=5$ ). No significant difference was observed between DHT- and placebotreated groups.

\section{ROS inhibition and eNOS uncoupling}

Binding of acetylcholine to its receptor on endothelial cells leads to the activation of eNOS. We measured expression and phosphorylation of eNOS in lung tissue, which is densely vascularized, as an alternative for the aortic tissues, because aortic tissue was not available in sufficient quantities due to the functional studies. We did not observe any effect of DHT treatment, although we obviously cannot exclude that there may be differences in eNOS expression and phosphorylation between lung and aorta tissues. eNOS signaling can be disturbed by ROS, which decrease available NO, induce eNOS uncoupling and decrease the effectiveness of eNOS (Fleming 2010). Both tempol and NAC are ROS inhibitors but acting through different mechanisms (Zafarullah et al. 2003, Simonsen et al. 2009, Wilcox 2010). BH4 is a cofactor of eNOS and in the presence of reduced BH4 levels eNOS uncoupling occurs, leading to superoxide production instead of NO (Fleming 2010, Roe \& Ren 2012). Since no differences in acetylcholine-induced aortic vasodilatation occurred after the treatment with NAC or tempol it is reasonable to suggest that ROS formation is not responsible for the decreased vasodilatation to acetylcholine in DHT-treated mice. In contrast, the increase in acetylcholine-induced aortic vasodilatation after treatment with $\mathrm{BH} 4$ implies that eNOS uncoupling was increased, leading to a disturbed eNOS function; however, we cannot explain why we did not observe increased ROS production as a consequence.

\section{Increase in Ar mRNA expression after DHT treatment}

We observed a strong increase in $A r$ mRNA expression in the chronically DHT-treated animals. This is in accordance with earlier studies reporting increased AR expression in endometrium of PCOS patients (Apparao et al. 2002,

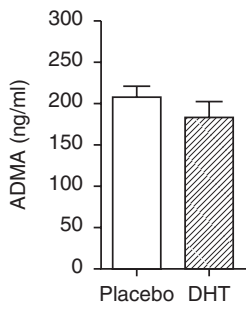

Figure 6

Serum levels of ADMA in mice chronically treated with a placebo $(n=8)$ or $\mathrm{DHT}(n=6)$ pellet. No significant difference was observed between DHTand placebo-treated groups.

Villavicencio et al. 2006), as well as in ovaries in a rat PCOS model (Zurvarra et al. 2009). It is known that AR signaling can be both genomic and nongenomic and may, in turn, activate other signaling pathways (Bennett et al. 2010). Thus, it is tempting to suggest that an increased AR signaling may underlie the reduced endothelial function (i.e. a decreased vasorelaxation to acetylcholine) observed in the aortas after treatment with DHT. Admittedly, no experimental evidence is reported in the literature to support this view.

\section{Endothelial dysfunction as a primary or secondary phenomenon}

Chronic androgen exposure can increase blood pressure in women with PCOS and rats treated chronically with DHT or testosterone displayed elevated blood pressure (Keller et al. 2011, Chinnathambi et al. 2013). Increased blood pressure can lead to decreased endothelial function. However, our PCOS mice also display a metabolic phenotype. To decide whether hyperandrogenemia directly induces endothelial dysfunction or whether this is primarily mediated through metabolic alterations, we also studied endothelial function in mice implanted

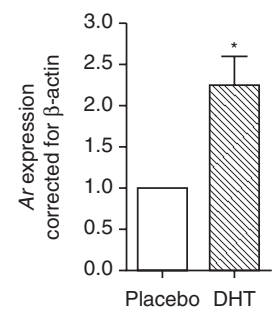

Figure 7

Ar mRNA expression in thoracic aortas of mice treated for 90 days with placebo $(n=5)$ compared with DHT-treated mice $(n=5)$. Values are corrected for the household gene $\beta$-actin. *Significantly different from placebo, $P<0.05$.

Published by Bioscientifica Ltd. 
with a 60-day DHT-release pellet, which resulted in lower serum DHT levels at the end of the experiment (60 days after implantation). These 60-day DHT-treated mice did not develop the metabolic or reproductive PCOS-resembling phenotype. Yet, these mice did show decreased vasorelaxation to acetylcholine to a similar extent as the 90-day DHT-treated mice. This suggests that the endothelial dysfunction observed upon DHT treatment most likely is a direct effect of androgens, not secondary, on metabolic changes.

In conclusion, our results in a DHT-induced mouse model for PCOS suggest that hyperandrogenemia specifically decreases the endothelium-dependent vasorelaxation, without deterioration of smooth muscle function. This study may initiate further investigations to resolve the mechanisms behind the vascular pathologies observed in PCOS patients.

\section{Declaration of interest}

The authors declare that there is no conflict of interest that could be perceived as prejudicing the impartiality of the research reported.

\section{Funding}

Dr A M was supported by the Netherlands Organization for Scientific Research (Vidi grant 917.11.349), whereas Prof. Dr C M V was supported by Consejo Nacional de Ciencia y Tecnología (CONACyT; project no. 60789; México D.F.).

Author contribution statement

J A Visser and A MaassenVanDenBrink contributed equally to this work.

\section{References}

Apparao KB, Lovely LP, Gui Y, Lininger RA \& Lessey BA 2002 Elevated endometrial androgen receptor expression in women with polycystic ovarian syndrome. Biology of Reproduction 66 297-304. (doi:10.1095/ biolreprod66.2.297)

Asuncion M, Calvo RM, San Millan JL, Sancho J, Avila S \& Escobar-Morreale HF 2000 A prospective study of the prevalence of the polycystic ovary syndrome in unselected Caucasian women from Spain. Journal of Clinical Endocrinology and Metabolism 85 2434-2438. (doi:10.1210/jc.85.7.2434)

Azziz R, Woods KS, Reyna R, Key TJ, Knochenhauer ES \& Yildiz BO 2004 The prevalence and features of the polycystic ovary syndrome in an unselected population. Journal of Clinical Endocrinology and Metabolism 89 2745-2749. (doi:10.1210/jc.2003-032046)

Bayrak T, Dursun P, Bayrak A, Gultekin M, Kolusari A, Cakir E, Ozyurt M \& Zeyneloglu HB 2012 Paraoxonase lactonase activity (PON-HTLase), asymmetric dimethylarginine (ADMA) and platelet activating factoracetylhydrolase (PAF-AH) activity in non-obese women with PCOS. Gynecological Endocrinology 28 874-878. (doi:10.3109/09513590.2012. 683068)
Bennett NC, Gardiner RA, Hooper JD, Johnson DW \& Gobe GC 2010 Molecular cell biology of androgen receptor signalling. International Journal of Biochemistry \& Cell Biology 42 813-827. (doi:10.1016/j.biocel. 2009.11.013)

Carmina E, Rosato F, Janni A, Rizzo M \& Longo RA 2006 Extensive clinical experience: relative prevalence of different androgen excess disorders in 950 women referred because of clinical hyperandrogenism. Journal of Clinical Endocrinology and Metabolism 91 2-6. (doi:10.1210/jc.20051457)

Charitidou C, Farmakiotis D, Zournatzi V, Pidonia I, Pegiou T, Karamanis N, Hatzistilianou M, Katsikis I \& Panidis D 2008 The administration of estrogens, combined with anti-androgens, has beneficial effects on the hormonal features and asymmetric dimethyl-arginine levels, in women with the polycystic ovary syndrome. Atherosclerosis $196958-965$. (doi:10.1016/j.atherosclerosis.2007.03.002)

Chinnathambi V, Balakrishnan M, Ramadoss J, Yallampalli C \& Sathishkumar K 2013 Testosterone alters maternal vascular adaptations: role of the endothelial NO system. Hypertension.

Davis SR, Knight S, White V, Claridge C, Davis BJ \& Bell R 2002 Preliminary indication of a high prevalence of polycystic ovary syndrome in indigenous Australian women. Gynecological Endocrinology 16 443-446.

Diamanti-Kandarakis E, Kouli CR, Bergiele AT, Filandra FA, Tsianateli TC, Spina GG, Zapanti ED \& Bartzis MI 1999 A survey of the polycystic ovary syndrome in the Greek island of Lesbos: hormonal and metabolic profile. Journal of Clinical Endocrinology and Metabolism 84 4006-4011. (doi:10.1210/jc.84.11.4006)

Durik M, Kavousi M, van der Pluijm I, Isaacs A, Cheng C, Verdonk K, Loot AE, Oeseburg H, Bhaggoe UM, Leijten F et al. 2012 Nucleotide excision DNA repair is associated with age-related vascular dysfunction. Circulation 126 468-478. (doi:10.1161/CIRCULATIONAHA.112. 104380)

Eftekhari S \& Edvinsson L 2010 Possible sites of action of the new calcitonin gene-related peptide receptor antagonists. Therapeutic Advances in Neurological Disorders 3 369-378. (doi:10.1177/1756285610388343)

Fleming I 2010 Molecular mechanisms underlying the activation of eNOS. Pflügers Archiv: European Journal of Physiology 459 793-806. (doi:10.1007/s00424-009-0767-7)

Friederich JA \& Butterworth JF 1995 Sodium nitroprusside: twenty years and counting. Anesthesia and Analgesia 81 152-162.

Furchgott RF \& Zawadzki JV 1980 The obligatory role of endothelial cells in the relaxation of arterial smooth muscle by acetylcholine. Nature $\mathbf{2 8 8}$ 373-376. (doi:10.1038/288373a0)

Glueck CJ, Morrison JA, Goldenberg N \& Wang P 2009 Coronary heart disease risk factors in adult premenopausal white women with polycystic ovary syndrome compared with a healthy female population. Metabolism 58 714-721. (doi:10.1016/j.metabol.2009.02.005)

Goodarzi MO, Quinones MJ, Azziz R, Rotter JI, Hsueh WA \& Yang H 2005 Polycystic ovary syndrome in Mexican-Americans: prevalence and association with the severity of insulin resistance. Fertility and Sterility 84 766-769. (doi:10.1016/j.fertnstert.2005.03.051)

Goodarzi MO, Dumesic DA, Chazenbalk G \& Azziz R 2011 Polycystic ovary syndrome: etiology, pathogenesis and diagnosis. Nature Reviews. Endocrinology 7 219-231. (doi:10.1038/nrendo.2010.217)

de Groot PC, Dekkers OM, Romijn JA, Dieben SW \& Helmerhorst FM 2011 PCOS, coronary heart disease, stroke and the influence of obesity: a systematic review and meta-analysis. Human Reproduction Update 17 495-500. (doi:10.1093/humupd/dmr001)

van Houten EL, Kramer P, McLuskey A, Karels B, Themmen AP \& Visser JA 2012 Reproductive and metabolic phenotype of a mouse model of PCOS. Endocrinology 153 2861-2869. (doi:10.1210/en.2011-1754)

Hudecova M, Holte J, Olovsson M, Lind L \& Poromaa IS 2010 Endothelial function in patients with polycystic ovary syndrome: a long-term follow-up study. Fertility and Sterility 94 2654-2658. (doi:10.1016/ j.fertnstert.2010.02.048)

Kravariti M, Naka KK, Kalantaridou SN, Kazakos N, Katsouras CS, Makrigiannakis A, Paraskevaidis EA, Chrousos GP, Tsatsoulis A \&

Published by Bioscientifica Ltd. 
Michalis LK 2005 Predictors of endothelial dysfunction in young women with polycystic ovary syndrome. Journal of Clinical Endocrinology \& Metabolism 90 5088-5095. (doi:10.1210/jc.2005-0151)

Keller J, Mandala M, Casson P \& Osol G 2011 Endothelial dysfunction in a rat model of PCOS: evidence of increased vasoconstrictor prostanoid activity. Endocrinology 152 4927-4936. (doi:10.1210/en.2011-1424)

Lakhani K, Leonard A, Seifalian AM \& Hardiman P 2005 Microvascular dysfunction in women with polycystic ovary syndrome. Human Reproduction 20 3219-3224. (doi:10.1093/humrep/dei199)

Lakhani K, Yang W, Dooley A, El-Mahdi E, Sundaresan M, McLellan S, Bruckdorfer R, Leonard A, Seifalian A \& Hardiman P 2006 Aortic function is compromised in a rat model of polycystic ovary syndrome. Human Reproduction 21 651-656. (doi:10.1093/humrep/dei399)

Manneras L, Cajander S, Holmang A, Seleskovic Z, Lystig T, Lonn M \& Stener-Victorin E 2007 A new rat model exhibiting both ovarian and metabolic characteristics of polycystic ovary syndrome. Endocrinology 148 3781-3791. (doi:10.1210/en.2007-0168)

McCredie RJ, McCrohon JA, Turner L, Griffiths KA, Handelsman DJ \& Celermajer DS 1998 Vascular reactivity is impaired in genetic females taking high-dose androgens. Journal of the American College of Cardiology 32 1331-1335. (doi:10.1016/S0735-1097(98)00416-1)

Meyer MR, Haas E, Prossnitz ER \& Barton M 2009 Non-genomic regulation of vascular cell function and growth by estrogen. Molecular and Cellular Endocrinology 308 9-16. (doi:10.1016/j.mce.2009.03.009)

Mulvany MJ \& Halpern W 1977 Contractile properties of small arterial resistance vessels in spontaneously hypertensive and normotensive rats. Circulation Research 41 19-26. (doi:10.1161/01.RES.41.1.19)

Rodin DA, Bano G, Bland JM, Taylor K \& Nussey SS 1998 Polycystic ovaries and associated metabolic abnormalities in Indian subcontinent Asian women. Clinical Endocrinology 49 91-99. (doi:10.1046/j.1365-2265. 1998.00492.x)

Roe ND \& Ren J 2012 Nitric oxide synthase uncoupling: a therapeutic target in cardiovascular diseases. Vascular Pharmacology 57 168-172. (doi:10.1016/j.vph.2012.02.004)

Roland AV, Nunemaker CS, Keller SR \& Moenter SM 2010 Prenatal androgen exposure programs metabolic dysfunction in female mice. Journal of Endocrinology 207 213-223. (doi:10.1677/JOE-10-0217)

Sara L, Nadasy GL, Antal P, Monori-Kiss A, Szekeres M, Masszi G, Monos E \& Varbiro S 2012 Pharmacological reactivity of resistance vessels in a rat PCOS model - vascular effects of parallel vitamin D(3) treatment. Gynecological Endocrinology 28 961-964. (doi:10.3109/09513590.2012. 683079)

Sasaki A, Emi Y, Matsuda M, Sharula , Kamada Y, Chekir C, Hiramatsu Y \& Nakatsuka M 2011 Increased arterial stiffness in mildly-hypertensive women with polycystic ovary syndrome. Journal of Obstetrics and Gynaecology Research 37 402-411. (doi:10.1111/j.1447-0756.2010. 01375.x)

Simonsen U, Christensen FH \& Buus NH 2009 The effect of tempol on endothelium-dependent vasodilatation and blood pressure. Pharmacology \& Therapeutics 122 109-124. (doi:10.1016/j.pharmthera. 2009.02.002)
Soyman Z, Noyan V, Tulmac M, Yucel A, Sagsoz N, Bayrak T, Bayrak A \& Cakir E 2011 Serum paraoxonase 1 activity, asymmetric dimethylarginine levels, and brachial artery flow-mediated dilatation in women with polycystic ovary syndrome. Fertility and Sterility 95 1067-1072. (doi:10.1016/j.fertnstert.2010.12.011)

Stepto NK, Cassar S, Joham AE, Hutchison SK, Harrison CL, Goldstein RF \& Teede HJ 2013 Women with polycystic ovary syndrome have intrinsic insulin resistance on euglycaemic-hyperinsulaemic clamp. Human Reproduction 28 777-784. (doi:10.1093/humrep/des463)

Suzuki M, Takamisawa I, Yoshimasa Y \& Harano Y 2007 Association between insulin resistance and endothelial dysfunction in type 2 diabetes and the effects of pioglitazone. Diabetes Research and Clinical Practice 76 12-17. (doi:10.1016/j.diabres.2006.07.033)

Villalon CM \& Centurion D 2007 Cardiovascular responses produced by 5-hydroxytriptamine: a pharmacological update on the receptors/ mechanisms involved and therapeutic implications. NaunynSchmiedeberg's Archives of Pharmacology 376 45-63. (doi:10.1007/ s00210-007-0179-1)

Villalon CM \& Olesen J 2009 The role of CGRP in the pathophysiology of migraine and efficacy of CGRP receptor antagonists as acute antimigraine drugs. Pharmacology \& Therapeutics 124 309-323. (doi:10.1016/ j.pharmthera.2009.09.003)

Villavicencio A, Bacallao K, Avellaira C, Gabler F, Fuentes A \& Vega M 2006 Androgen and estrogen receptors and co-regulators levels in endometria from patients with polycystic ovarian syndrome with and without endometrial hyperplasia. Gynecological Oncology 103 307-314. (doi:10.1016/j.ygyno.2006.03.029)

Vitale C, Fini M, Speziale G \& Chierchia S 2010 Gender differences in the cardiovascular effects of sex hormones. Fundamental \& Clinical Pharmacology 24 675-685. (doi:10.1111/j.1472-8206.2010.00817.x)

Wilcox CS 2010 Effects of tempol and redox-cycling nitroxides in models of oxidative stress. Pharmacology \& Therapeutics 126 119-145. (doi:10.1016/j.pharmthera.2010.01.003)

Wild RA 2002 Long-term health consequences of PCOS. Human Reproduction Update 8 231-241. (doi:10.1093/humupd/8.3.231)

Wild RA, Carmina E, Diamanti-Kandarakis E, Dokras A, Escobar-Morreale HF, Futterweit W, Lobo R, Norman RJ, Talbott E \& Dumesic DA 2010 Assessment of cardiovascular risk and prevention of cardiovascular disease in women with the polycystic ovary syndrome: a consensus statement by the Androgen Excess and Polycystic Ovary Syndrome (AE-PCOS) Society. Journal of Clinical Endocrinology and Metabolism 95 2038-2049. (doi:10.1210/jc.2009-2724)

Zafarullah M, Li WQ, Sylvester J \& Ahmad M 2003 Molecular mechanisms of N-acetylcysteine actions. Cellular and Molecular Life Sciences 60 6-20. (doi:10.1007/s000180300001)

Zurvarra FM, Salvetti NR, Mason JI, Velazquez MM, Alfaro NS \& Ortega HH 2009 Disruption in the expression and immunolocalisation of steroid receptors and steroidogenic enzymes in letrozole-induced polycystic ovaries in rat. Reproduction, Fertility, and Development 21 827-839. (doi:10.1071/RD09026)

Received in final form 14 May 2013

Accepted 3 June 2013

Accepted Preprint published online 3 June 2013 http://joe.endocrinology-journals.org DOI: 10.1530/JOE-13-0094
() 2013 Society for Endocrinology Printed in Great Britain 